\title{
The Effect of Automatic Teller Machines on Efficiency of Banks (case study: commercial banks of Kermanshah city)
}

\author{
Bahar Hasani Esfehani ${ }^{1}$, Mehdi Sadeghi ${ }^{2} *$ \\ ${ }^{1}$ Master Student of Business Management, Kermanshah Branch, Islamic Azad University, Kermanshah, Iran \\ ${ }^{2}$ *Faculty member Department of EducationManagement, Kermanshah Branch, Islamic Azad University, \\ Kermanshah, Iran
}

\begin{abstract}
The purpose of the present study was to analyze the effect of Automatic Teller Machine (ATM)on efficiency of banks. Population of the present study is commercial banks of Kermanshah and the time period of the study is 2015, since population was 2925 individuals, using Cochran formula 365 individuals were considered as samples for the study using stratified sampling. Accordingly, data of a questionnaire filled by bank experts was considered for analysis of the research hypotheses and the effect of variables such as number of Automatic Teller Machine, the trading value of Automatic Teller Machines were used. The method of study was applied research and respecting the method of application it was descriptive and survey and respecting the type of data it was a quantitative research. For data analysis methods such as Kolmogorov-Smirnov, KMOBartlett test and the Structural Equation Modeling was used. Also, software of SPPS20 and AMOS 20 were used. Result showed that indexes of number of ATMs (2.07) ATM's trade Values (2.14) have the most effect on efficiency of banks, respectively.
\end{abstract}

Keywords: Automatic Teller Machine (ATM), efficiency, number of ATMs, ATMs trade values.

\section{Introduction}

The main purpose of economic institutions was to obtain the most inputs with the least resources; this issue refers to improving efficiency of institutions (Safarnia et al, 2012). Financial and monetary institutions especially commercial banks for their direct influence on economic and social development of countries are very important (Golbazkhani Pour et al, 2013). Today, efficiency is considered as a culture and landscape in the entire domains of life and work of human being and considered as the source of development and economic growth (MohamadiAbandashki, Kheradyar, and Kjeradyar, 2014). Since in partial and macro studies and planning the issue of measuring efficiency is a common issue, in most of the cases there are many limitations such as lack of statistics and information and limitedness of calculations for subsections. In Iran's economy for weakness of statistical system for measurement and analysis of efficiency some economic sections including services section is less concerned (services contains about 52\% of GDP) and most of the studies were devoted to productive sectors of economy. On the other hand, benefits of using ATMs in banks and outside of banks called Automatic Teller Machine centers are to the extent that there is no doubt about wide usage of them; therefore, in the present study tried to analyze the effect of Automatic Teller Machines of efficiency of bank by measuring variables such as number of ATMs, and ATMs trade values.

\section{ATM Kiosks}

An Automatic Teller Machine that is called passenger bank is an electronic machine that lets bank customers to receive money from their accounts or checking their balance any time automatically without needs to cashier. Most of the Automatic Teller Machines are equipped with possibilities such as transferring money between banking accounts, transferring money or check or even buying stamp for customers. In modern Automatic Teller Machines sing plastic cards having a magnetic strip the user is recognized and by the way information of user account will be coded and by means of a password called PIN entering into system became possible. If user enters the PIN wrongly, most of the ATMs do not return the card to user. This action is anticipated for increasing security and decreasing any misusing from ATMs. In developed ATMs the duty of reading and registering customer information will be done on smart cards. ATMs are constituted of a secure cryptoprocessor that usually by means of a host computer compatible with IBM located in a secure physical cover. Most of the ATMs are connected to interbank network, because in this way it is possible to receive money from an ATM other than ATM of your account bank. But, to deposit money to your account, you need to use the ATM of your account bank. This possibility in suitablein traveling especially when your bank has no branch of ATM in that area, or while connection of ATMs to similar foreign ATMs there is this possibility for passengers to exchange their money in foreign countries with the least of costs (Soltani, 2004). 
The Effect of Automatic Teller Machines on Efficiency of Banks (case study: commercial banks of ..

\section{A review of ATMs statistics}

The first ATM in the world was launched in 1967 by Barclays bank and from that time until now, ATM is considered as one of the 10 superior inventions of century that is listed as one of the 30 most important inventions during human history. It is a machine that many consider it as the best innovation of banks in spite of negative attitudes to banks over the world. Automatic Teller Machines not only revolutionized banking industry, but also changed the people's living style that such changes are known to people properly. Following the world, Iran was not distanced from this technology and in 1972, the first generations of ATMs called Automatic Kiosk by BimehBazargan Bank was installed in Iran. Now after 33years, according to the last statistics published on the Website of central bank until the end of 201440463 ATMs were installed in Iran that we can say by considering 80 million population of Iran for every 1977 person there is one ATM. When this statistic in the world is 2433 ATMs per individual, this ratio is 750 per ATM in United States as a developed country. According to statistics the mean of withdrawal from ATMs in the US is 60 dollars that is about $1,900,000$ rial that is generally close to maximum withdrawal ratio in Iran that is 2,000,000 rial. In addition, in the USA, each user goes to ATM 7 times per month averagely, and statistics showed that sale of shops and markets with one or several ATMs, 20\% than the time when were not installed, number of machines increased. Currently, since there are 3 million MTA machine in the world in servicing, every 5 minutes one new ATM is added to them. As mentioned until the 20 March 2015, 40463 Automatic Teller Machines were installed in Iran that most of them belong to Meli bank (6480), Saderat (4692), Melat (3847), Tejarat (3774), Sepah (2581), respectively. It means that $52 \%$ of the entire ATMs of the country belong to 5 banks (central Bank, the office of payment systems, 2015).

\section{Efficiency in servicing organizations}

Theoretically, definition of efficiency in services sector like efficiency in production sector means the ratio of outputs to inputs. But, the main problem in measuring efficiency of services in function is the method of definition and measuring final output. Many servicing organizations are lacking tangible and physical output. Therefore, definition of output, criteria and indexes of measuring outputin services section has more complexity than production and industry sector that requires precision and more research. On the other hand, every type of servicing have the unique way and the purposes, aims and methods are different from each other. Therefore, criteria of efficiency in different services are different.

\section{Literature Review}

Aghamohamadi (2006) in a study entitled as "analyzing the method of calculating the entire price of services by Automatic Teller Machines from banking system was studies by case study in Saderat Bank of Iran and result of the study showed that installing ATMs in traffic places is the main factor of decreasing costs for transactions. Yavari (2006) studied the quality of introducing technology of ATMs and sale stands in offering baking services and customer's tendency in using them in the Agriculture bank of Tehran. Data was analyzed using a questionnaire containing 39 questions and result of his research indicated that proper placing for Machines, diversity of servicesand trusting machines in the views of users and others influences their intention in using ATMs, but educational and advertising activities and knowledge of customers is not so influential on ATMs. Owu et al (2009) in a study entitled as "the effect of frequent ATMs on efficiency of banking expenses in Taiwan were studied and indicated that application of ATMs could decrease costs and by decreasing costs, banks were able to achieve a higher level of performance.

\section{Purposes of the study}

- Understanding the effect of number of ATMs on efficiency of banks.

- $\quad$ Understanding the effect of ATMs trade values on efficiency of Banks.

\section{Research hypotheses}

First hypothesis: there is a positive and significant relationship between number of ATMs and efficiency of banks.

Second hypothesis: there is a positive and significant relationship between ATMs trade values and efficiency of banks.

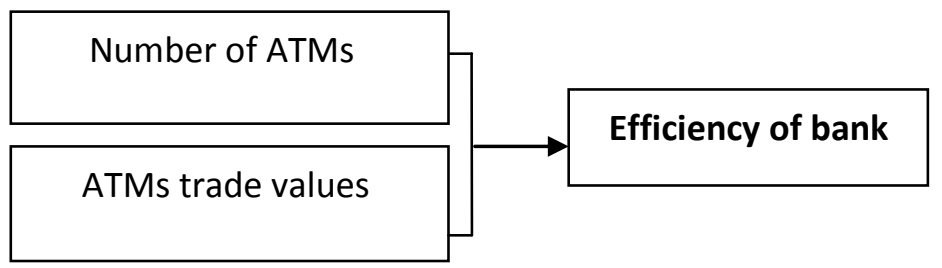

Diagram 1: conceptual model of the study 
The Effect of Automatic Teller Machines on Efficiency of Banks (case study: commercial banks of ..

\section{Methodology}

The method of the study was applied research with respect to purpose. As well the applied method is on the basis of the method of collecting descriptive and correlative information. The study was performed using survey study mainly referring to library studies including books, articles, journals, research reports, documents and existent documents and using internet, questionnaire and interview with managers, experts regarding related issues. Population of the study was the entire workers trading banks in Kermanshah city. The study is a filed study spatially, because, data of the study were among population and collected using samples and questionnaire. Necessary data in the present study were collected using a close questionnaire on the basis of Likert's five item spectrum that is done according to previous works and ideas of experts; the questionnaire is prepared in two sections. The first section is demographic information of respondents and the second section includes close tests that analyzes the research variables, and the questionnaire of the present study is prepared on the basis of the research model.

After data collection and eliciting them for data analysis at first descriptive statistics is used for adjusting data and determining statistical indexes is related to research variables. Also, inferential statistics was used for analysis of research hypotheses. For data analysis SPSS and AMOS software were used.

\section{Population}

Table 1: population of the study

\begin{tabular}{|l|l|l|l|l|l|l|l|l|}
\hline & Meli & Sepah & Melat & Saderat & Tejarat & Refah & Post Bank & Sum \\
\hline Number of Personnel & 866 & 394 & 513 & 465 & 393 & 220 & 74 & 2925 \\
\hline Number of branches & 90 & 52 & 51 & 72 & 54 & 24 & 13 & 356 \\
\hline
\end{tabular}

Population of this study is the entire experts of information technology and workers of commercial banks in Kermanshah. Population of the study was $(\mathrm{N}=2925)$ and size of the samples according to Cochran formula was $\mathrm{n}=365$.

\section{Samples}

Using stratified methodology a number of experts of banking affair were selected for responding.

Sampling methodology

In this method at first using a primary sampling the mean and variance were calculated. Then using Cochran formula we calculate the size of samples.

$$
n=\frac{N S^{2} Z_{\frac{\alpha}{2}}^{2}}{N d^{2} \bar{Y}^{2}+S^{2} Z_{\frac{\alpha}{2}}^{2}}
$$

In this formula

$\mathrm{d}=$ permissible error

$\bar{Y}=$ mean of samples

The value of normal distribution with the confident level of $1-\alpha=Z_{\frac{\alpha}{2}}$

Size of population $=\mathrm{N}$

Size of samples $=\mathrm{n}$

At first using Cochran formula the size of samples were estimated. For this reason, the primary samples including 30 individuals were selected:

The mean including 30 individuals were 17.6159 and variance of this population was 3.357.

Also, $\mathrm{N}=2925, \mathrm{~d}=0.01$, and $Z_{\frac{\alpha}{2}}=1.96$. Therefore, size of samples that should be selected from the entire classes is:

$$
n=\frac{2925 \times 53.357 \times(1.96)^{2}}{2925 \times(0.01)^{2} \times(17.6159)^{2}+3.357 \times(1.96)^{2}}=364.01 \cong 365
$$

Therefore, the selected size from the entire classes was 365 individuals.

Specifying the size of samples from each class: 
The Effect of Automatic Teller Machines on Efficiency of Banks (case study: commercial banks of ..

In this research we have 7 banks and each of these banks is considered as one class. To select the size of samples in each of the classes we use the method of appropriate allocation. In this method the size of samples in classes is appropriate to the size of classes.

If the entire size of population is $\mathrm{N}$, then the general size of samples is $\mathrm{n}$, the size of $\mathrm{h}^{\text {th }}$ class is measured by $\mathrm{N}_{\mathrm{k}}$. Therefore, for each class, size can be estimated as follow:

$n_{h}=n \times \frac{N_{h}}{N}, \quad h=1,2, \ldots, 10$

Banks are considered as classes. Here $\mathrm{N}=2925$ and $\mathrm{n}=365$ and there are 7 classes. Therefore, as follow there is 365 samples. For example, like the following table there is a sample including 108 individuals selected from Meli Bank.

Table 2: specifying the size of samples in each of the classes

\begin{tabular}{|l|l|l|}
\hline classes & Class size $) N_{h}($ & Sample size $) n_{h}($ \\
\hline Meli bank & 866 & $n_{1}=365 \times \frac{866}{2925}=108$ \\
\hline Sepah bank & 394 & $n_{1}=365 \times \frac{394}{2925}=49$ \\
\hline Melat Bank & 513 & $n_{1}=365 \times \frac{513}{2925}=64$ \\
\hline Saderat Bank & 465 & $n_{1}=365 \times \frac{465}{2925}=58$ \\
\hline Tejarat Bank & 393 & $n_{1}=365 \times \frac{393}{2925}=49$ \\
\hline Refah Bank & & $n_{1}=365 \times \frac{220}{2925}=28$ \\
\hline Post bank & 220 & $n_{1}=365 \times \frac{74}{2925}=9$ \\
\hline Total & 74 & 365 \\
\hline
\end{tabular}

\section{Stability of the questionnaire}

\section{Data Analysis}

One of the features of measurement instrument is stability. The stated concept deals with this issue, that measurement tool in the similar conditions to what extent has similar results. One of the most common methods of analyzing the questionnaire is Cronbach's Alpha. Table 3 is related to stability of questionnaire.

Table 3: stability of questionnaire

\begin{tabular}{|c|c|}
\hline Number & Cronbach's Alpha \\
\hline 8 & 0.859 \\
\hline
\end{tabular}

According to the stated table the value of Cronbach's Alpha for analysis of the stability of the questionnaire is 0.859 and since it is more than 0.70 ; therefore, the present questionnaire has an acceptable stability.

Demographic features of statistical sample

In this section demographic features of statistical samples were presented. Features that were concerned are conditions of respondents regarding gender, education, age, servicing experience and number of selected samples from each bank.

Frequency distribution of gender: From among the entire 365 individuals, who responded to questions, 98 individuals (27\%) were women and 267 individuals were (73\%) were men.

Frequency distribution of education: from among samples 198 individuals were diploma and AA (54\%), 146 individuals were license $(40 \%)$ and 21 individuals $(6 \%)$ were MA.

Frequency distribution of age: from among selected individuals, 25 persons were from 25 to 30 years old (6.8), 151 individuals were from 31 to $35(41.4 \%), 178$ individuals were from 36 to 40 years $(48.8 \%)$ and 11 individuals were more than $40(3 \%)$. 
The Effect of Automatic Teller Machines on Efficiency of Banks (case study: commercial banks of ..

Frequency distribution of working experience: 9 individuals $(2.5 \%)$ had working experience less than 5 years, 103 individuals (28.2\%) were from 5 to 10,181 individuals (49.6\%) were from 10 to 15,69 individuals (18.9\%) were from 15 to 20 years and finally 3 individuals (8\%) had working experience more than 20 years.

Frequency distribution of the number of selected samples from Banks 108 individuals (30\%) of respondents were from Meli Bank, 49 individuals (13\%) were from Sepah Bank, 64 individuals (18\%) were from Melat Bank, 58 individuals (16\%) were from Saderat Bank, 49 individuals (13\%) were from Tejarat Bank, 28 individuals (8\%) were from Refah Bank, and 9 individuals (2\%) were from Post Bank.

\section{Normality Test of Data}

For analysis of normality of distributing variables Kolmogorov-Smirnov test was used. Ho in this test is normality of distributing variables. If the sig level of the test is more than $0.05, \mathrm{H} 0$ is accepted, and we conclude that distributing the considerable variable is normal.

Table 4: result of Kolmogorov-Smirnov test for analyzing the following of data from normality distribution

\begin{tabular}{|l|l|l|l|l|}
\hline Variables & mean & Standard deviation & Value of Kolmogorov-Smirnov statistics & Sig level \\
\hline Number of ATMs & 4.26 & 0.822 & 0.286 & 0.069 \\
\hline ATMs trade values & 4.13 & 0.885 & 0.352 & 0.12 \\
\hline
\end{tabular}

According to table 4, since the sig level of variables is more than 0.05 ; therefore, we conclude that both variables have a normal distribution.

\section{Standardizing the instrument of measuring the research concepts}

As the purpose of the study was access to a model for causal relationship between variables, therefore, the model of causal modeling should be used. This method compounds cause and effect information on the basis of a specific theory, describes the relationship between variables and provides a basis for inference. Casual inferences that are on the basis of types of correlation may specify the relationship between observable and latent variables. In other words, in casual modeling, the goal is to obtain quantitative estimations of casual relationships among a series of variables. In this study to access the model of study, Structural Equation Modeling was used that is on the basis of casual relationships between variables. The most important feature of this technique in its flexibility regarding application is considered as a wide theoretical framework, possibility of cooperation of latent variables, application of multiple sizes, possibility of making error, coordination of distributive assumptions and possibility of working with types of data. For applying the method of Structural Equation Modeling at first variables for shaping the model should be specified. The first stage of appointing the casual model was determination of variables that are shaping a theoretical framework for the study. Variables of the model are classified into two eendogenous and exogenous and were inserted inside the model. Definition of variables in the model on the basis of studies required in previous researches was done. Accordingly, the set of related variables with purposes and questions of the study were introduced and were ready for completion analyses. Below, it is necessary to introduce structures related to variables.

\section{The model of measuring the variable number of ATMs}

For factorial analysis at first KMO-Bartlett test was used. Result of KMO-Bartlett test is shown in table 5.

Table 5: result of KMO-Bartlett test for variable of number of ATMs

\begin{tabular}{|l|l|l|}
\hline Criteria for sufficiency of sampling KMO & 0.508 \\
\hline \multirow{3}{*}{ Bartlett test } & K2 & 541.69 \\
\cline { 2 - 3 } & Degree of freedom & 6 \\
\cline { 2 - 3 } & Sig level & 0.00 \\
\hline
\end{tabular}

According to the results, it is possible to do the stages of factorial analysis on data. The value more than 0.05 of KMO statistics represents sufficiency of sampling and the sig level of 0.000 for Bartlett test in which represents appropriateness of the referenced factorial model. The ratio of calculated KMO is 0.508 and since it is more than 0.50; therefore, calculations represent sufficiency of sampling. In the next stage, the number of latent factors should be introduced. In table 6 , result of specifying the latent factors were offered on the basis of special amounts.

Table 6: the entire specified variance for latent factors of the variable "number of ATMs"

\begin{tabular}{|l|l|l|l|l|l|l|}
\hline \multirow{2}{*}{ Factor } & \multicolumn{3}{|l|}{ The primary spatial amount } & \multicolumn{3}{l|}{ Total square bars extracted factors } \\
\cline { 2 - 7 } & Total & $\begin{array}{l}\text { Variance } \\
\text { percentage }\end{array}$ & $\begin{array}{l}\text { Collective } \\
\text { percentage }\end{array}$ & Total & $\begin{array}{l}\text { Variance } \\
\text { percentage }\end{array}$ & $\begin{array}{l}\text { Collective } \\
\text { percentage }\end{array}$ \\
\hline 1 & 1.15 & 28.95 & 28.95 & 1.15 & 28.95 & 28.95 \\
\hline
\end{tabular}


The Effect of Automatic Teller Machines on Efficiency of Banks (case study: commercial banks of ..

According to table 6, the column of primary special amounts shows the number of latent factors of the study and number of general special values more than 1 shows latent factor. Therefore, the column of special values of the variable number of ATMs introduces a factor with special amounts more than 1; therefore, the suggestive factorial analysis has one factor.

The form of measurement model of the variable number of ATMs is shown in the form of standard estimation. Factorial loads of the model in the state of standard estimation of the level of effect for each variable or items is shown in describing and determining variance of variable scores or the main factor. In other words, factorial load shows the level of correlation for each observer variable (question of questionnaire) with variables (factors). When the entire factorial loads in one factor are greater than 0.3 , there will be validity of the structure that is convergent. Table 7 shows the result of factorial analysis separately for each question in the variable of external factor.

Table 7: factorial load of indexes related to the variable of external factor

\begin{tabular}{|l|l|}
\hline Index & Factorial load of the model (regression coefficients) \\
\hline $\mathrm{q} 1$ & 1.000 \\
\hline $\mathrm{q} 2$ & 1.07 \\
\hline $\mathrm{q} 3$ & 0.70 \\
\hline $\mathrm{q} 4$ & 0.46 \\
\hline
\end{tabular}

These factorial loads are shown in diagram 2.

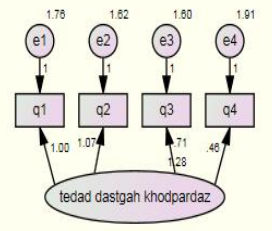

Diagram 2: the model of measuring the variable of number of ATMs

In this study for appropriate analysis of the model indexes related to fitting of the model are provided in table 8 which are used here.

Table 8: fitting indexes of the measurement model for the variable number of ATMs

\begin{tabular}{|l|l|l|l|}
\hline & Result & Value & Title of index \\
\hline The root mean square error of approximation & Approval of model & 0.000 & RMSEA \\
\hline Goodness of fit & Approval of model & 0.998 & GFI \\
\hline Modified goodness of fit index & Approval of model & 0.988 & AGFI \\
\hline Normalized fit index (BentlerBonet) & Approval of model & 0.990 & NFI \\
\hline Comparative fit index & Approval of model & 1.000 & CFI \\
\hline Incremental fit index & Approval of model & 1.000 & IFI \\
\hline
\end{tabular}

According to the result, the entire fitting indexes of the stated model are in acceptable domain and therefore, appropriateness of collected data is appropriate with the model. Therefore, final fitting of the model for number of ATMs was approved.

The model of measuring the variable of ATMs trade values

For factorial analysis at first KMO-Bartlett test was used.

Result of KMO-Bartlett test was shown in table 9.

Table 9: result of KMO-Bartlett test for the variable of ATMs trade values

\begin{tabular}{|l|l|l|}
\hline Criteria of sufficiency sampling KMO & 0.612 \\
\hline \multirow{3}{*}{ KMO-Bartlett test } & $\mathbf{K 2}$ & 34.43 \\
\cline { 2 - 3 } & Degree of freedom & 6 \\
\cline { 2 - 3 } & Sig level & 0.00 \\
\hline
\end{tabular}

According to the results it is possible to accomplish the stages of approval factorial analysis on data. The value more than 0.05 of KMO statistics represents sufficiency of sampling and confident level of 0.00 that for Bartlett test shows appropriateness of the applied factorial model. 
The Effect of Automatic Teller Machines on Efficiency of Banks (case study: commercial banks of ..

The rate of calculated KMO is equal to 0.612 , and since it is more than 0.50; therefore, calculations represent sufficiency of sampling. In the next stage the number of latent factors should be introduced. In table 10 result and number of latent factors according to special value were offered.

Table 10: the entire specified variance for latent factors of the variable ATMs trade values

\begin{tabular}{|l|l|l|l|l|l|l|}
\hline \multirow{2}{*}{ Factors } & \multicolumn{3}{|l|}{ Primary special values } & \multicolumn{3}{l|}{ Total square bars extracted factors } \\
\cline { 2 - 7 } & Total & $\begin{array}{l}\text { Variance } \\
\text { percentage }\end{array}$ & $\begin{array}{l}\text { Collective } \\
\text { percentage }\end{array}$ & Total & $\begin{array}{l}\text { Variance } \\
\text { percentage }\end{array}$ & $\begin{array}{l}\text { Collective } \\
\text { percentage }\end{array}$ \\
\hline 1 & 1.89 & 47.32 & 47.32 & 1.89 & 47.32 & 47.32 \\
\hline
\end{tabular}

According to table 10, the column of primary special amount shows latent factors of the study and number of total special amounts higher than 1 represents latent factors. Therefore, the column of special values for the variable ATMs trade values, introduces a factor with special value greater than 1; therefore, suggested factorial structure will have one factor.

The form of measurement model shows the variable of ATMs trade values. Factorial load of question 13 was meaningless and removed from the model. Factorials loads of the model shows the influence value for each of the variables or shows items in describing and specifying the variance of variable score or the main factor. In other words, factorial load shows correlative amount for each observer variable (question of questionnaire) with variables (factors). Table 11 shows result of factorial analysis for each question in the variable ATMs trade values.

Table 11: factorial load of indexes related to the variable of ATMs trade values

\begin{tabular}{|c|c|}
\hline Index & Factorial load of the model (regression coefficients) \\
\hline $\mathrm{q} 12$ & 1.000 \\
\hline $\mathrm{q} 14$ & 0.904 \\
\hline $\mathrm{q} 15$ & 1.63 \\
\hline $\mathrm{q} 16$ & 1.19 \\
\hline
\end{tabular}

These factorial loads are shown in diagram 3.

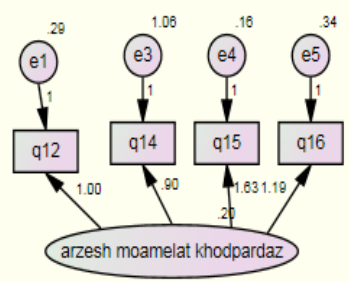

Diagram 3: the model of measuring the variable ATMs trade values

The entire factorial loads are more than 0.3 ; therefore, validity of construction is convergent.

In this study, for analysis of the appropriateness of the model indexes related to fitting of the model were offered that are used in table 12 .

Table 12: indexes of fitting the model of measuring the variable of ATMs trade values

\begin{tabular}{|c|c|c|c|}
\hline & Result & Value & Title of index \\
\hline The root mean square error of approximation & Rejection of model & 0.14 & RMSEA \\
\hline Goodness of fit & Approval of model & 0.963 & GFI \\
\hline Modified goodness of fit index & Approval of model & 0.815 & AGFI \\
\hline Normalized fit index (BentlerBonet) & Approval of model & 0.926 & NFI \\
\hline Comparative fit index & Approval of model & 0.951 & CFI \\
\hline Incremental fit index & Approval of model & 0.954 & IFI \\
\hline
\end{tabular}

According to the results we can claim that the entire fitting indexes of the model are provided in an acceptable domain; therefore, appropriateness of collected data is proper with the model. Accordingly, fitness of final model for ATMs trade values was approved. 
The Effect of Automatic Teller Machines on Efficiency of Banks (case study: commercial banks of ..

Structural model of the study (analysis of the main model of the study)

The model of structural equation modeling is provided below. Table 13 shows the eta (effect) value of variables.

Table 13: analysis of research hypotheses using Structural Equation Modeling

\begin{tabular}{|c|c|c|c|}
\hline Research hypotheses & Eta & Sig level & Result of hypothesis \\
\hline $\begin{array}{l}\text { There is a positive and significant relationship between number } \\
\text { of ATMs and bank efficiency. }\end{array}$ & 2.07 & 0.03 & $\begin{array}{l}\text { Approved in } 95 \% \\
\text { confident }\end{array}$ \\
\hline $\begin{array}{l}\text { There is a positive and significant relationship between ATMs } \\
\text { trade values and bank efficiency. }\end{array}$ & 2.14 & 0.021 & $\begin{array}{l}\text { Approved in } 95 \% \\
\text { confident }\end{array}$ \\
\hline
\end{tabular}

69.

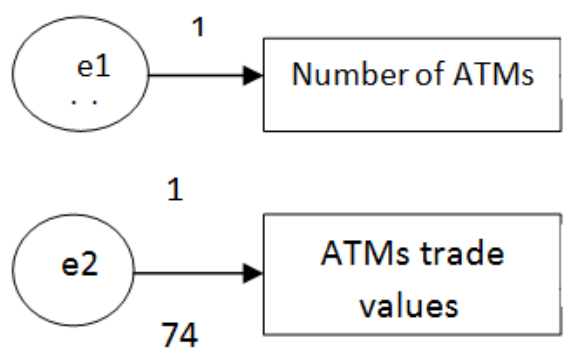

e3

2.08 .

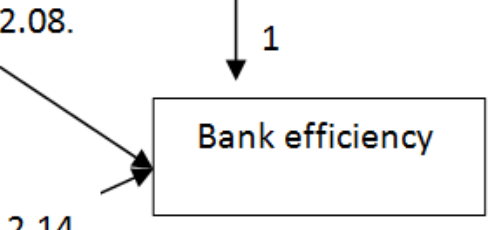

2.14
43.74

Diagram 4: model of Structural Equation Modeling

\section{Conclusion and Suggestions}

Today, the servicing industry is changing in the world. New technologies have changes the methods of offering services to customers in many servicing organizations. The strongest forces for changes in the competitive environment of current times are information technology and telecommunications. Geographical distance has lost its meaning and accessibility of services, simplicity and rapid distribution of services caused competitive advantages for organizations including banks. For competition in this complex environment, business should offer the newest and most attractive services to customers. In this way, many banks over the world offered electric services. Because they know that the principal of their survival is the speed of offering services and awareness from needs of customers. Currently a growing part of customers who intended to do their banking services using electronic systems without referring to banks are forming. Bank customers using electronic banking services can do their banking operation at their interested time and place and banks receive a low expense for decreasing the number of workers and decreasing of banking branches. In fact, using e-banking in daily affaires is not dos and don'ts, but it is an inevitable affaire. On the other hand according to the role of international communications, ignoring this pervasive wave in the office of financial-credit systems of the country caused digging the country in a global isolation. On the other hand, the main purpose of economic institutions was to obtain the most input that refers to improving efficiency of institutions. Financial and monetary institutions especially commercial banks for their direct influencing on economic and social development of countries are highly influential. Currently efficiency as a culture and landscape is posed in the entire aspects of works and life of human being and it is the source of development and economic growth. This culture and its landscape are so that by organizing it the best of results will be achieved. One of the subjects that should be organized is banking industry which is considered as one of the pivotal activities in economic growth of every country, so that organizing this industry provides the grounds for promotion and optimal performance of them. Doubtless, each activity requires capital and financial resources, as well as the significant role of banks and financial institutions. Therefore, for their influential role in economic activities, investigating efficiency performance of them is important. Banking management according to economic conditions of past and future should be followed by past and future economic conditions, modification and improving banking services, marketing, budgeting, innovation in offering services, competitiveness with other financial organizations and finally increasing efficiency in supervised units. According to the first hypothesis regarding the number of ATMs and their role on efficiency of commercial banks in Kermanshah city the following issues are suggested: the proper number of ATMs, the normal number of ATMs, new number of ATMs that caused attracting customers, increasing the number of machines and accessibility to them in all places are considered. Result of the present study was in line with the result of study by Aou et al (2009) in application of new ATMs which were able to decrease costs and by the way banks were able to achieve a high level of performance. Also, according to the second hypothesis of the study, the value of transactions by ATMs resulted in efficiency of commercial banks in Kermanshah city and it is suggested that the following items be considered: the rate of ATMs trade values from card to card item, the rate of ATMs trade values from the item of receiving cash, the rate of ATMs trade values from e-charge of mobiles, the rate of ATMs trade values from paying installations, 
The Effect of Automatic Teller Machines on Efficiency of Banks (case study: commercial banks of ..

the rate of ATMs trade values from, the rate of ATMs trade values from checking balances. Result of this hypothesis was in line with the results of the study by Aghamohamadi. In addition, some issues should be considered; including codification of laws allowing banks to be creative regarding electronic banking services, and cooperation with banks regarding purchasing equipment required for electronic banking.

\section{References}

[1]. Aghamohammadi, A. (2006). Studying the methods services costs by ATMs from banking network, MA thesis, Iran's banking higher education institute.

[2]. Central Bank (2014).The office of payment systems.

[3]. Soltani, Sh. (2004). ATM Kiosk. Central Bank of Islamic Republic of Iran, the office of online payments.Aban, 1-9.

[4]. Safarnia, H., Zainali, S., Bastani, R. (2012). Measuring efficiency of general hospitals of social welfare in the country using Malem Quist index. Hakim journal,16 (1)spring. 65-71.

[5]. GolbazKhani Pour, G, FazelYazdi, A. TahariMehrJerdi, M.H (2013). Evaluation and specification of optimal structures of resources and indexes of financial performance of banks using none-parametric approaches (case study: accepted banks in Tehran's stock market. The Journal of Investment Knowledge. 2 (7) 85-104.

[6]. MohamadiAbdankeshi, S. Kheradyar, S. (2014). Studying the effect of efficiency factors on profitability in some private banks.International conference of economy, accounting, management and social sciences.Polish.1-14.

[7]. Yavari, A. (2006). Analysis of the quality for introducing ATM technology of banking and sale terminals and customers' tendency to use them. MA thesis of higher education for Iran's electronic banking. 